\title{
V6. EVENTOS ADVERSOS PÓS-VACINAIS NOTIFICADOS À VI- GILÂNCIA EPIDEMIOLÓGICA DO MUNICÍPIO DE CAMAÇARI, BAHIA NO PERÍODO DE 2014 A 2015.
}

Laís Torres Saraiva ${ }^{1}$; Ana Paula Nogueira²; Eloisa Barreto Bacelar².

${ }^{1}$ Unidade Básica de Saúde do Gravatá/ Secretaria de Saúde Camaçari-BA;

${ }^{2}$ Coordenação de Vigilância Epidemiológica/Dep. de Vigilância à Saúde Camaçari-BA.

INTRODUÇÃO Todo e qualquer evento adverso pós-vacinal (EAPV) deve ser notificado e encaminhado à Vigilância Epidemiológica, para que os mesmos sejam investigados e esclarecidos, e assim seja estabelecida uma conduta adequada frente à ocorrência desses agravos.

OBJETIVO O objetivo deste estudo foi conhecer e caracterizar os eventos adversos notificados, as fontes notificadoras e a população atingida pelos eventos adversos pós-vacinação, de acordo com sexo, idade, tipos de eventos, tempo entre a administração do(s) imunobiológico(s) e a ocorrência do evento adverso, e imunobiológico(s) administrado(s).

METODOLOGIA Estudo epidemiológico descritivo de abordagem quantitativa, com dados obtidos por meio das fichas de notificação de EAPV que foram notificadas pelas Unidades de Saúde à Vigilância Epidemiológica do Município de Camaçari-Ba no período de 2014 a 2015.

RESULTADOS Através dos dados coletados e analisados observou-se que houve 92 notificações de EAPV do ano de 2014 a 2015, destas 34,78\% foram notificadas por enfermeiros, $30,43 \%$ notificados por técnicos em enfermagem e $34,78 \%$ por profissionais que não identificaram a categoria profissional pertencente. Quanto aos estabelecimentos que notificaram, 56,52\% foi notificado por Unidades Básicas de Saúde (UBS), 31,52\% por Programa de Saúde da Família (PSF), 7,60\% pelo Hospital do Município, e 3,26\% por outras unidades. Quanto à faixa etária dos pacientes notificados, observou-se que a maioria apresentava entre 0 e 10 anos, representando 68,47\%, sendo 51,08\% do sexo feminino. Quanto ao tempo decorrente da administração do imunobiológico e aparecimento de evento adverso, 44,56\% ocorreram nas primeiras 24 horas. Quanto ao tipo de evento, 89,13\% foram eventos não-graves. A vacina isolada 
que mais causou reação adversa foi a Pentavalente (35,86\%). Os eventos adversos mais notificados foram dor, rubor e calor (71,73\%) seguido de edema (20,65\%).

CONCLUSÃo Os resultados apontam fragilidades no que se refere às subnotificações e ao preenchimento das fichas de notificação pelos profissionais de Saúde, uma vez que das 40 Unidades de Saúde que pertencem ao Município de Camaçari, apenas 14 notificaram com periodicidade, bem como, as fichas de notificação demonstraram preenchimento incorreto e incompleto, comprometendo assim a qualidade da informação produzida. Sugere-se com esse estudo que haja capacitações com o intuito de sensibilizar às equipes de saúde sobre a importância de se notificarem, corretamente, os eventos adversos, para que os mesmos possam ser investigados e desta forma adotadas condutas adequadas, garantindo assim a credibilidade do Programa Nacional de Imunizações assim como a manutenção da segurança da população.

PALAVRAS-CHAVE evento adverso pós-vacinal, imunobiológico, notificação. 